\title{
THE USE OF ACCOUNTING INFORMATION IN BANK LENDING DECISIONS*
}

\author{
PAUL DANOS $\uparrow$, DORIS L HOLT $\ddagger$ and EUGENE A. IMHOFF, JR $\dagger$ \\ + Graduate School of Business Administration, The University of Michigan; \\ ‡ Carlson School of Management, University of Minnesota
}

\begin{abstract}
This paper examines the impact of accounting information on the sequential judgments of experienced bank loan officers using realistic lending cases in an experimental setting. The findings suggest that loan officers reach a high level of confidence early in the lending process based on summarized accounting information and other general background data. When, later in the process, factors concerning the firm's financial plans and their underlying assumptions are varied, lenders adjust their confidence in whether or not to grant the loan in the expected directions, even when the subsequent evidence disconfirms their original positions.
\end{abstract}

Accounting information is used in many business decisions, including the very important area of bank lending. Even though financial accounting is said to be developed to assist external users in their business decisions, with the two primary external user groups identified as investors and creditors (FASB, 1978), there is very little empirical work that examines lending decisions and how creditors process accounting data.

We examine the impact of accounting information on the sequential judgments of bank loan officers using realistic condensed lending cases in an experimental setting. The study reflects a high degree of external validity, and provides new insights into how and when various types of accounting information are used in banks' credit-granting decision process.

The results of our research suggest that lenders reach a high level of confidence in their credit-granting decisions very early in the information gathering and evaluation process. This initial confidence is based on summarized financial accounting data and other background information. At the same time, lenders' confidence in their judgments at subsequent stages of the information gathering and evaluation pro- cess are materially altered by more detailed forms of accounting data. Even in cases where subsequent information disconfirms prior judgments, lenders respond by revising their confidence in the credit-granting decision consistent with the nature of the subsequent evidence. While this result is consistent with the common finding that strong initial confidence is obtained early in the decision process, it is inconsistent with the many studies that find disconfirming evidence not to be searched for and/or to be ignored once a strong initial impression has been formed.

The study provides evidence that accounting data have a material impact on lending decisions, and that summarized basic financial statement data, collected independently of the client borrower early in the process, have the greatest impact on their decisions for the class of borrower examined in this study. These results point to a previously unexplored source of data for future investigation into accounting's role in the creditgranting process.

The next section of the paper discusses the nature of the credit-granting process, and the subset of credit-granting decisions examined in this study. The third section of the paper

-The authors appreciate the financial support of the Touche Ross Foundation, which made this study possible. We appreciate the assistance of Carol Frost, Jaysri Sankaran and Jacob Thomas. 
describes the research design and hypotheses, with the results and analysis reported in the fourth section. The final section summarizes the results and implications for future research.

\section{THE LENDING ENVIRONMENT}

\section{Synopsis of the lending process}

The first step in our project was to learn as much as possible about when and how accounting information is actually used in the creditgranting process. Based on structured but openended interviews with chief lending officers at three major banks in Detroit, two major banks in Chicago and three large San Francisco banks, we found the following generalizations to hold.

1. For small borrowers (e.g. sales of less than $\$ 10-\$ 15$ million) the quality of the accounting data is very inconsistent, sometimes of limited use to lenders. Financial plans are generally unavailable. Bank loans are an important source of capital for these borrowers.

2. For medium size borrowers (e.g. sales between $\$ 20$ and $\$ 40$ million) the accounting information is generally of acceptable quality and very important to the credit granting process. Financial plans are frequently available and of use to lenders. Bank loans are an important source of capital for these borrowers.

3. For large borrowers, the accounting information is normally of a high quality, usually audited, and often more detailed than what is reported to investors in annual reports. Bankers' ability to obtain all accounting data may be limited by the borrower. However, detailed nonpublished data are often not necessary for lenders to evaluate credit applications. These bank loans are frequently a small part of the capital required by large borrowers, who use public debt, leases, etc., as their major sources of capital.

Based on this analysis, we determined that the medium sized borrowers would be of greatest interest for this study. The inconsistency in smaller borrowers caused research design and validity problems we chose not to deal with, while large borrowers might be better evaluated using publicly available data (e.g. analysis of bond ratings) rather than the experimental approach used here.

Focusing our attention on medium sized borrowers, we interviewed lenders to identify those aspects of the sequence of data gathering and analysis that were common to the evaluation process across lending institutions. We focused on the lending decision for a new client. This situation provided the most unambiguous setting for evaluating the complete sequence of steps in the lending process. Decisions regarding existing borrowers were based heavily on track record and interpersonal relationships, making it difficult or impossible to isolate the effect of accounting information and creating serious internal validity problems.

We found the sequence of the lending decision process for new clients to be relatively easy to standardize, enabling generic lending cases to be developed around the following three phase process.

Phase 1. Examine publicly available data on potential borrower to make a preliminary judgment on the quality of the proposed loan.

Pbase 2. Make personal contact with prospec. tive borrower, normally at borrower's place of business, to size up the borrower's operations and future financial and operating plans.

Phase 3. Perform detailed credit analysis and evaluation of historical and forward-looking financial data to determine the likelihood of a successful loan.

These three phases of the credit-granting decision provide a framework for evaluating lenders' judgments as a sequential process. Detailed financial accounting data are the most dominant part of the information set in phase 3 , where credit analysis is performed. However, rather than confining the experiment to manipulations of phase 3 accounting data, our experiment investigates the entire sequence to determine the relative importance of information at all three phases. ${ }^{1}$ We note that while accounting data are

\footnotetext{
'One drawback with generic cases focusing on phase three manipulations alone was the inconsistent role of the lending officer in the credit analysis. Lending officers at some banks do their own credit analysis while other banks employ separate credit analysts who work with or for lending officers.
} 
the dominant ingredient in phase 3 , important accounting data are introduced at all three phases of information gathering and evaluation.

\section{Details of lending phases}

Phase one of the credit evaluation process involves gathering background information on a prospective borrower, including a brief history of the company and a credit report. This background data includes highly summarized financial report information, such as a credit rating, details about location(s), number of employees, when the company began, names of key officers, and so on. When current, the credit reports from financial services such as Dun \& Bradstreet (D \& B) are considered by lenders to be the most useful source of information in phase 1 . These credit reports contain data from financial statements voluntarily submitted to the credit service by the most closely held companies. The D \& B report also indicates whether the statements are audited, reviewed or compiled, the name of the CPA firm (if any), any unusual features of the data, and other pertinent information. The combination of the credit reports and the lender's knowledge of the client's officers, major owners, lines of business and industry position (facilitated by such sources as Robert Morris Surveys) provide the background data included in phase 1.

Phase 2 of the process involves a personal "sizing up" of the borrower's business prospects and managerial skills. This phase normally includes an on location visit by the lender. Any background data missing from what is normally collected in phase 1 is usually collected during phase 2 . Also, phase 2 normally contains a discussion with the client as to the purpose of the loan, their future operating plans and their financial plans for the repayment of the loan.

Detailed historical and forward-looking accounting data are normally either collected by the lender during their visit with the borrower, or else forwarded to the bank soon after the visit.
These accounting data help lenders to assess the need for the loan, its purpose, and the quality of the borrower's organization. In conjunction with the interpersonal aspects of the visit these financial accounting data provide important signals to lenders regarding the borrower's production capabilities, financial planning and control procedures, and the overall integrity of the management team. The availability of detailed operating and financial data during the visit is an important signal to lenders in assessing manage. ment's financial preparedness.

In phase 3 the lender performs detailed evaluations of the historical and forward-looking accounting data. This process is designed to determine whether the forward-looking data provide for the successful repayment of the loan from future operations, and whether the underlying assumptions about the future along with historical facts from past performance are sufficiently supportive of such a plan. The phase 3 analysis, along with the other data collected in earlier phases culminates in a decision to grant or not grant the proposed loan. The decision is made by an individual or a group, depending on the lending officer's authorized lending limit and other bank policies. ${ }^{2}$

\section{Factors affecting lending}

We expected loan officers to develop high levels of confidence in lending judgments early in the process, but also to modify their confidence in response to signals they receive during the process.

Judgment research has shown that in settings lacking clear and quick outcome feedback, decision-makers display extreme and inappropriate confidence in the quality of their judgments (Einhorn \& Hogarth, 1978). Oskamp (1965) demonstrated that such over-confidence occurs even among experienced professionals making routine professional judgments. In addition, once settled on a hypothesis, judges typically do not consider evidence that is discon-

\footnotetext{
${ }^{2}$ For example, a given lending officer might have a limit of $\$ 200,000$, meaning he or she can approve loans up to $\$ 200,000$ without committee approval, but is required to make a presentation to a committee for loans in excess of $\$ 200,000$. Within the same bank there may be some officers with, say, $\$ 1,000,000$ limits, while others may have $\$ 250,000$ limits, and so on.
} 
firming or consistent with alternative hypotheses (Elstein et al., 1978; Lord et al., 1979; Koriat et al., 1980).

However, we believe that bank loan officers work in a decision-making environment that fosters a different pattern of confidence modification. First, they must anticipate defending their loan decisions before a loan committee. Such a setting has been shown to enhance people's memory of cues and to incorporate more cues in their judgments (Ebbesen \& Konecni, 1975). Loan officers encounter a wide variety of loan situations both personally and through reports of colleagues (Holt, 1984). This may allow them to imagine alternative hypotheses and, as Einhorn \& Hogarth (1982) posit, reduce the credibility of a favored hypothesis. Moreover, there is evidence that expert decision-makers who must justify their judgments are able to de. tect and respond to subtle variances in routinely analyzed data (Danos et al., 1984).

\section{EXPERIMENTS AND HYPOTHESES}

\section{The decision variable}

The three phases of the information-gathering and evaluation process provide a framework within which lenders' sequential judgements are examined. The decision variable of interest elicited from lenders at each stage in this information gathering and evaluation process is the confidence in their judgment that the loan would be granted or not granted. Our search of the literature revealed that very little work had been done on the lending decision, and that the decision variable used on some widely referenced prior work focused on the interest rate as the decision variable (Libby, 1979). However, our interviews with bankers revealed that interest rate is not of great importance during the decision process. It seems that interest rate is more an institutional/ market condition variable rather than one considered by individual loan officers in assessing potential borrowers. The rate of return for a loan is affected by interest rate and other factors such as the mix of other services a client might commit to in conjunction with a loan.
Alternatively, it is very realistic to assume that lenders have a feel for how likely it is that a proposed loan will be granted at any stage of the information-gathering and evaluation process. That the process has three fairly distinct and uniform phases to it enhances their ability to provide interim judgments at these three points in the process. Given that our interest in this experiment is to learn more about the relative importance of the information found in the three different phases, we evaluate changes in confidence in the grant/not grant decision after each of the three stages.

In order to compare bankers' decisions across lending institutions and lenders, we examine lenders' confidence in their decision to grant or not grant a proposed loan by recording three separate observations for each case, we allow each subject's change in confidence to be the measurement of interest. Also, at the conclusion of each case we elicit the lender's subjective probability that the loan described in the case will be "fully serviced".

\section{Experimental instruments}

Many different variables included in the three phases of data collection and analysis were candidates for manipulation. From the set of realistic possibilities, we chose to evaluate several dimensions considered to be important in the lending process. Our discussions with bankers suggested that their decision processes were influenced by risk class. As a result, we developed two corporate cases, one a financially strong and one a financially weak case, for use in the experiments. Once the basic financial risk level was established, a large number of potential manipulated variables became "fixed" in order to maintain the overall realism of each case. For example, historical financial accounting data are a key element in risk assessment, and the manipulation of these historical data would not be possible if they changed the inherent risk manifested in the data.

A second manipulated variable was the initial availability of the prospective financial data during the phase 2 visit to the borrowers. While all borrowers could be expected to have historical 
data on hand, only those who had prepared forward-looking data consistent with a feasible term loan would be ready to provide such data during the visit. The prospective accounting data provided a signal of management's planning competence and the degree of attention they had devoted to how the proposed loan would be employed and repaid.

The final manipulated variable also came from the forward-looking accounting data. Even in cases where forward-looking data are not initially available at the first visit, we assumed that such data would be presented to the bank before the lending process advanced to phase 3 . The nature of the assumptions underlying the forward-looking operating results was able to be realistically manipulated without conflicting with the underlying riskiness implied by the historical data. The assumptions motivating the prospective accounting data were of great interest to lenders in their assessment of the successful payback of the loan.

The variations examined in phase 1 (P1), phase 2 (P2), and phase 3 (P3) of the lending process are outlined in Fig. 1. The accumulation of data implicit in this sequencing is consistent with the decision process described by lending officers except that, for experimental purposes, we employ discrete elicitation points. The actual decision may be continuous.

The experiment was designed primarily to examine how confidence is formed and modified in a lending situation. This was accom. plished by measuring how the lenders' confidence changed over time and how variations in accounting data affected their confidence.

We manipulated the risk variable as a withinsubject treatment so that each subject received
Phase 1

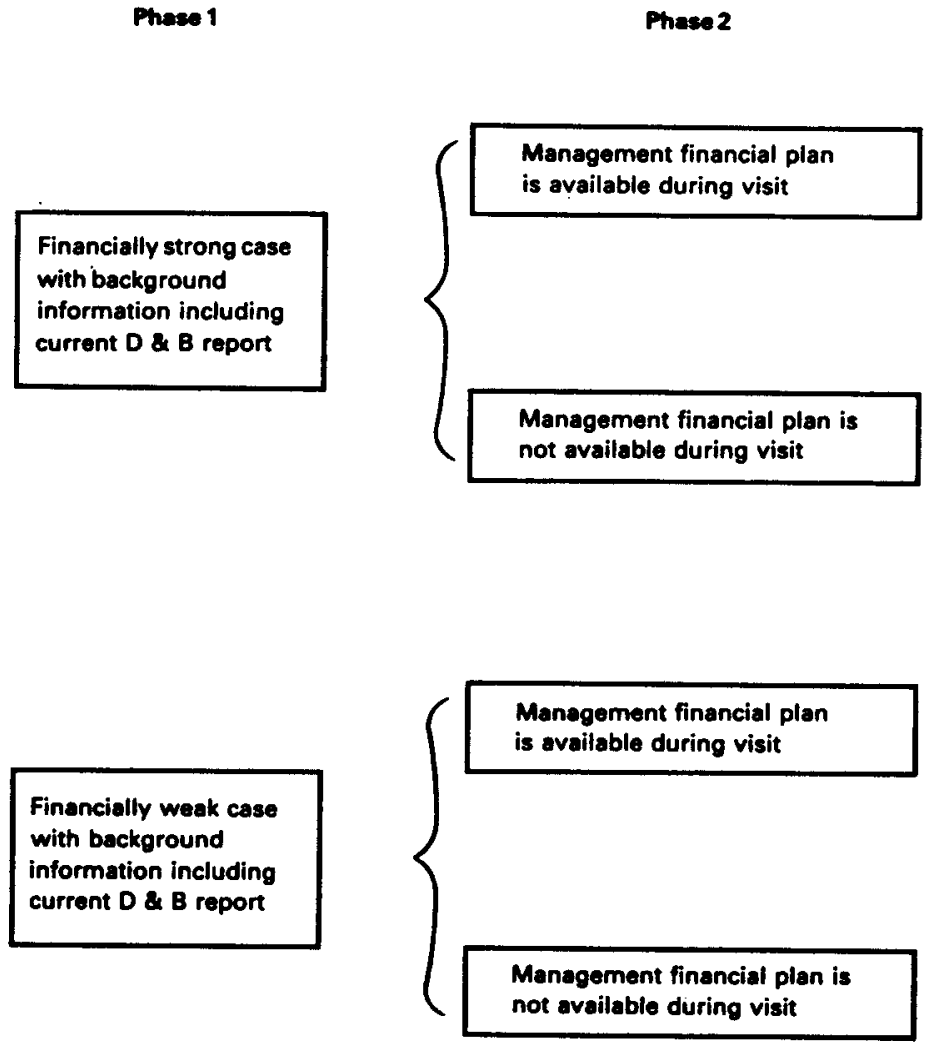

Phese 3
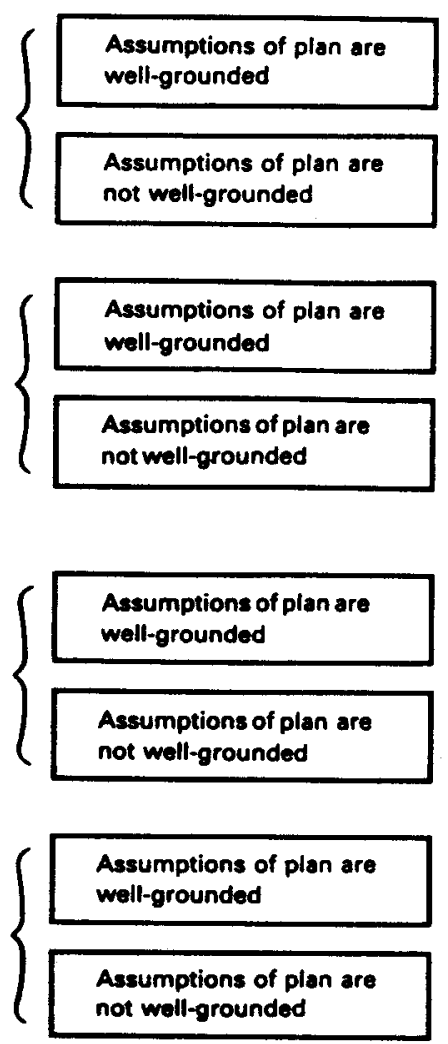

Fig. 1. Variations in information available to lenders in a typical lending setting. 
both the financially strong and the financially weak cases. The risk level was established by using summarized historical financial data and their corresponding actual risk "rating" as prepared by Dun \& Bradstreet for two actual companies. The accounting data used as treatments in the second and third stages of the evaluation process for each case were introduced on a between-subject basis. Each subject received the same level of the phase 2 and phase 3 treatments for both cases. Each subject provided three responses concerning their confidence in the grant/not grant decision for each of the two cases, one response after each phase. The responses called for the lender to predict on the basis of the data received to that point - after phase 1 , after phase 2 and after phase 3 , whether or not the loan would be granted, and then to indicate how confident they were that their prediction would be the correct one in 100 identical cases. The repeated measurements taken after introducing phase 2 and phase 3 provided an indication of the change in their confidence attributable to the new information in phase 2 and phase $3 .^{3}$

At the conclusion of each case, we asked each subject to evaluate the probability that, if granted, the loan described in the case would be fully serviced. This follow up question provided a check of our primary elicitation concerning their confidence in the grant/not grant decision, since confidence should be associated with their belief that the loan would be fully serviced.

\section{Subjects and administration}

The experiments were administered to $\mathbf{5 2}$ subjects at five major midwest and west coast banks. The lenders participated in groups of from 2 to 15 subjects in their respective bank's facilities, and were randomly assigned to treatment groups. The time to complete the experi- ments ranged from 65 to 95 minutes, with an average time of 75 minutes. Information provided to the subjects was closely controlled by the researchers, and none of the experimental materials were revealed to the participating banks until administration of the experiments.

We administered the experiments in person, providing a brief and uniform introduction and then remained at hand to answer any questions. Neither the order of presentation nor the cases themselves appeared to affect the time spent, with most subjects spending approximately equal time on the two cases. Very few questions were asked once the practice set materials were completed.

\section{Testable bypotbeses}

The experiment was designed to permit us to evaluate the impact of the three manipulated variables on lending judgments. On the basis of our fieldwork, we believed that the risk level would be a significant factor, but we were uncertain as to how it might interact with the other data provided.

In addition, we were interested in the pattern of responses for each case. How confident would lenders be after the first phase? As they received additional information in the second and third stage, how would their confidence in their judgment change? Would judgments change from grant to not grant or vice versa? Would the detailed financial reports analyzed in phase 3 sig. nificantly increase lenders' confidence? Is a higher level of confidence attained earlier in the process with nonrisky borrowers versus risky borrowers? By observing the patterns of responses we expected to gain insight into these previously unexplored issues.

We expected high confidence levels beginning at phase 1 as consistent with previous studies. However, the fieldwork also helped us

\footnotetext{
Samples of the experimental materials are available from the authors upon request.

"The researchers presented a brief verbal introduction and worked through a "practice set" with the subjects to familiarize them with the experimental instruments and judgment elicitation, answering any questions concerning the task during the practice session. This introduction took between 8 and 13 minutes to complete, depending on the presenter and the questions. Once the subjects were comfortable with the experimental instruments, they were free to work through the two (randomly ordered) cases and the "concluding questions" at their own pace.
} 
develop additional expectations at variance with the previous findings that subjects fail to search for or to use disconfirming evidence. Lenders told us that the availability of forward-looking accounting data signaled management planning competence, as did the quality of the assumptions upon which the data were based. We expected, therefore, that the confidence of our lender subjects would be modified consistent with the direction of these variables. In other words, the availability of well grounded forward-looking accounting data (a positive signal) would increase their confidence in a "grant" decision and decrease their confidence in a "not grant" decision.

\section{RESULTS}

Our results are reported in two parts. The first deals with the bankers' sequence of responses concerning their confidence in the grant/not grant decision elicited at three point in each case. The second part deals with the bankers' evaluation of the likelihood that a loan like the one described in the case would be fully serviced if it were granted.

\section{Results of confidence experiments}

The subjects were nearly unanimous about the basic grant/not grant decisions. For the financially weak case, 48 of 52 bankers judged that the loan would not be granted after the initial data revealed in phase 1 , with one additional banker changing from "grant" to "not grant" after phase 3. For the financially strong case 47 of 52 subjects initially judged that the loan would be granted, with three more switching to "grant" during the experiment.

As expected, lenders' overall level of confidence in their judgments increased as additional information was provided. Table 1 shows the overall mean level of confidence after each of the three phases of information was revealed in the two cases (without regard to other manipulated variables).

For the financially weak case, the initial level of confidence in their judgments after phase 1
TABLE 1. Mean confidence in judgements (all subjects, all treatments)

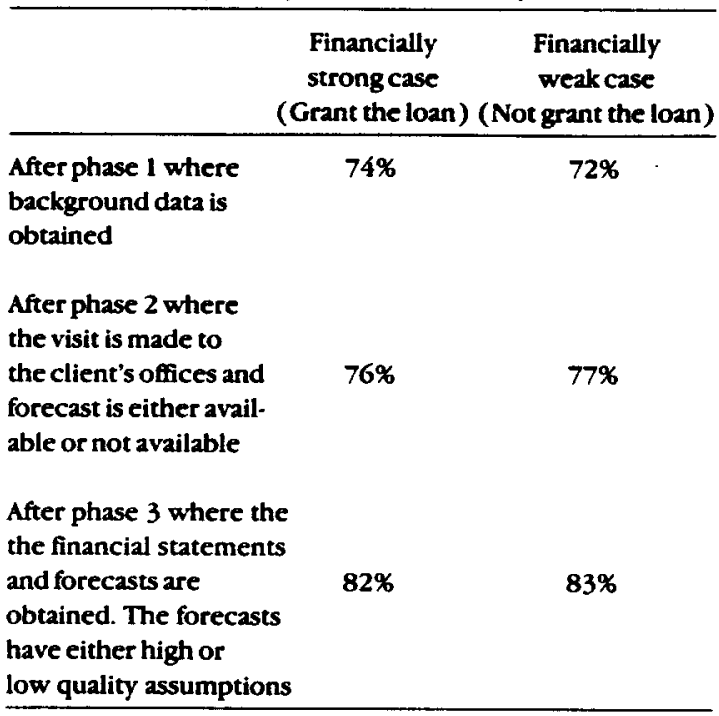

was quite high (72), suggesting that a great deal of information is obtained even before the lender meets with a prospective borrower. The meeting and information revealed in phase 2 is associated with an increase in confidence for the financially weak case, from 72 to 77 or +5 , while the detailed analysis of historical and forwardlooking financial data in phase 3 resulted in a slightly greater increase in confidence (from 77 to 83 or +6 ). For the financially strong case, the subjects initial average confidence in their judg. ments was somewhat higher than for the financially weak case ( 74 vs 72 ), providing evidence that lenders have a great deal of confidence in their expected lending judgments prior to ever meeting with a new client. The signals from the meeting in phase 2 had only a moderate positive impact on average confidence (from 74 to 76 or +2 ), while the detailed historical and forecasted financial data once again had a great effect on average confidence (from 76 to 82 or +6 ). On average, lenders predicted after phase 3 that in 82 of 100 cases like the financially strong case the loan would be granted.

We note that the data in phase 1 contained highly summarized financial data while phase 3 revealed detailed financial statement data. Based on the high initial confidence levels after phase 1 
and the significant increase in confidence after phase 3, we suggest that financial statement data, both historical and prospective, play a pivotal role in the lending decision process. The results are consistent with the premise that botb highly summarized financial statement data from inde. pendent sources and detailed historical and prospective financial statement data and financial ratios normally examined in phase 3 contain information that is useful to lenders.

Of particular interest was the relatively high level of initial confidence in the lending judg. ment after phase 1 alone. This outcome provides new evidence concerning the importance of basic financial statement data and other facts prepared by independent services and purchased by lenders as a primary source of initial information about a prospective client. The importance of the information and analysis provided by these services should not be understated. The analysis of financial statements of closely held companies provided by services such as Dun \& Bradstreet may influence lending decisions as much as bankers own direct analysis of detailed financial statements. It seems likely that other research might find Dun \& Bradstreet analysis useful in evaluating economic aspects of smaller closely held businesses.

Within the overall results reported in Table 1 , we examined the effect of two manipulated accounting variables that provided important information to lenders: initial availability of forward-looking accounting data $(A)$ and the quality of the assumptions used to prepare the forward-looking data $(Q)$. Tables 2 and 3 report the ANOVA results of the experiment for the two cases separately. 5 The ANOVA results for between-subject manipulations of $A$ and $Q$ are reported separately from the within-subject effects concerning the time sequence of confidence measures (designated $T$ for timing effects) and their interactions with $A$ and $Q$. The results are quite different for the two cases. The manipulated variables ( $A$ and $Q$ ) tend to have less of a systematic effect on the sequential confidence judgments in the financially weak case (Table 2) when compared to the financially strong case (Table 3 ). While the manipulation for the quality of the forecast assumptions $(Q)$ introduced in the final set of information (phase 3 ) was important in both cases $(p=0.07$ in Table 2 and $p=0.00$ in Table 3 ), the initial availability of the forecasts $(A)$ introduced in phase 2 was only significant in the financially strong case (Table $3, p=0.00$ ). The mean changes in confidence reported at the top of Tables 2 and 3 reveal similar patterns. With the exception of one change in Table 3 , lenders responded to the additional information with an increase in confidence. The exception occurred in the financially strong case when lenders discovered low quality forecast assumptions in phase 3, the final information set, after finding forecasts available during their visit. In response to this combination of treatments lenders reduced their average confidence that the loan would be granted. ${ }^{6}$

The pattern of changes in confidence for the financially strong case generally reveals "good news" levels of manipulated variables having a greater confidence-increasing effect on lenders GRANT predictions than "bad news" manipulations. The opposite is true for the financially weak case, where "bad news" manipulations increase lenders' confidence in their NOT GRANT predictions more than "good news" manipulations.

The overall patterns revealed in Table 1 are augmented by the results reported in Tables 2 and 3, which show the effects of confirming and disconfirming levels of information within the phase 2 and phase 3 data sets. We see that initial availability of forward-looking data from phase 2 has less impact on lender confidence than does the quality of the assumptions provided in phase

\footnotetext{
'This simplifies the analysis. ANOVA results with the two cases as a within-subject variable do not alter the conclusions or the strength of the results.

${ }^{6}$ Recall that the information provided in each of the last two phases includes more than the manipulated variable. Only if the manipulated variable is relatively important and of a disconfirming nature would we expect 2 decline in lenders' average confidence concerning the grant/not grant decision.
} 
TABLE 2. Financially weak case

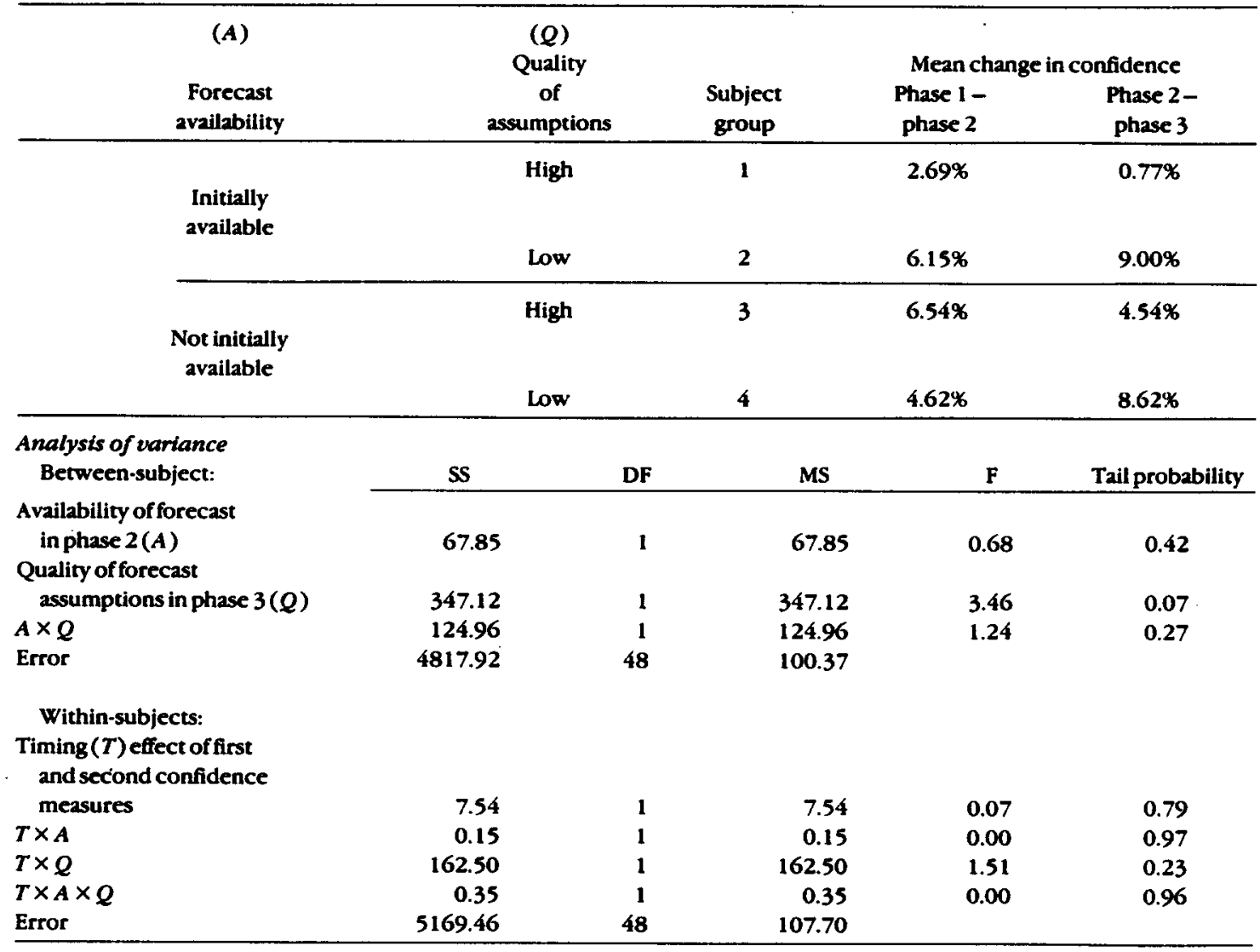

3. For the financially weak case, even as lenders approached high levels of confidence that the loan request would not be granted, their average confidence in the not grant decision increased at a much slower rate when presented with high quality assumptions. Our fieldwork led us to expect that both detailed historical data and forward-looking data would be important elements in lending decisions for companies similar to our cases. However, the quality of the assumptions concerning future accounting performance was the important accounting attribute normally found in the phase 3 data that offered a realistic variable to manipulate without contradicting the historical financial data provided in phase $1 .^{7}$ The importance of forward-looking accounting data is well documented in the accounting literature (e.g. Brown et al., 1985), with the predictive role of accounting data established as an objective by the FASB's Conceptual Framework (FASB, 1978). Here, we find empirical evidence supporting the usefulness of forward-looking accounting data in a major class of credit-granting decisions, lending further credence to their

\footnotetext{
The detailed historical data in phase 3 needed to be consistent with the earlier data (from phase 1) to maintain realism since Dun \& Bradstreet reports are rarely at variance with the detailed financial statements. Likewise, the forward-looking data were effectively required for the class of borrowers examined here, with the availability of these data (in phase 2 ) and the assessed quality of the underlying assumptions (in phase 3) representing important and realistic attributes that were capable of manipulation without confounding.
} 
TABLE 3. Financially strong case

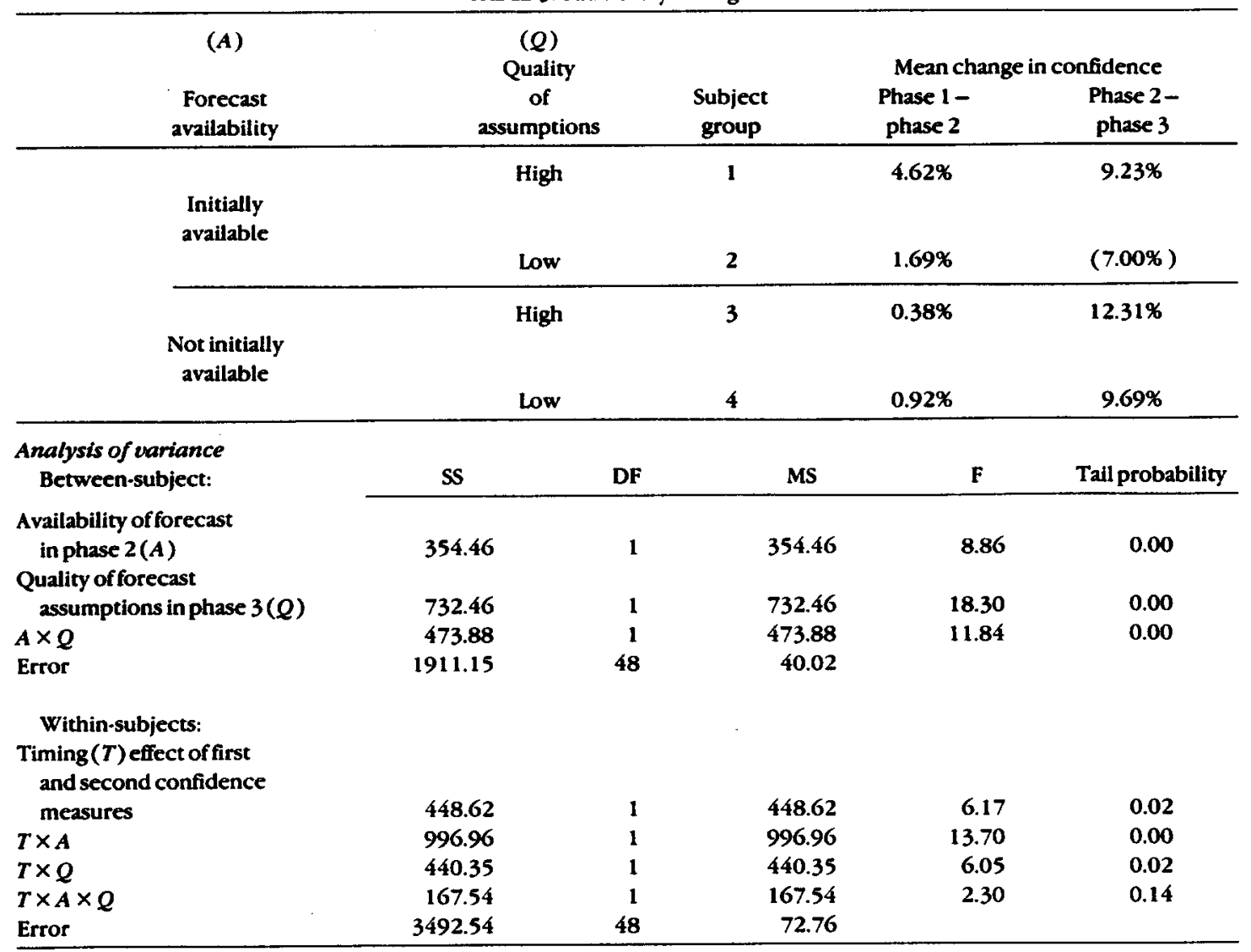

information content.

\section{Likelibood of fully serviced loan}

The second set of results supported the efficacy of our primary tests. These results concerning the likelihood that the loan in each case will be fully serviced are analyzed in a $2 \times 4$ ANOVA reported in Table 4 . The two variables, risk (at two levels) and treatment concerning forward. looking data (at four levels equal to the four combinations of treatments $A$ and $Q$ in Fig. 1) were both significant. The loan for the financially weak case was perceived as much less likely to be fully serviced than that of the financially strong case loan which speaks to the perceived quality of the two loans. Although the risk level was certainly dominant in terms of explanatory power, the four combinations of treatments regarding forward-looking accounting data were also significant at the 0.05 level. Note that the accounting treatments are still a between-subject manipulation here. This result provides further evidence of the importance of prospective accounting information in lenders' judgments of the overall quality of the loan.

\section{SUMMARY AND CONCLUSIONS}

These experiments, conducted with experienced lending officers, suggest that the manipulated variables were influential in the context of the decision tasks examined. The perceived risk level of the borrower had a significant impact on how subsequent information was apparently used. Also, we note that average lender confi- 
TABLE 4. Likelihood that loan will be fully serviced

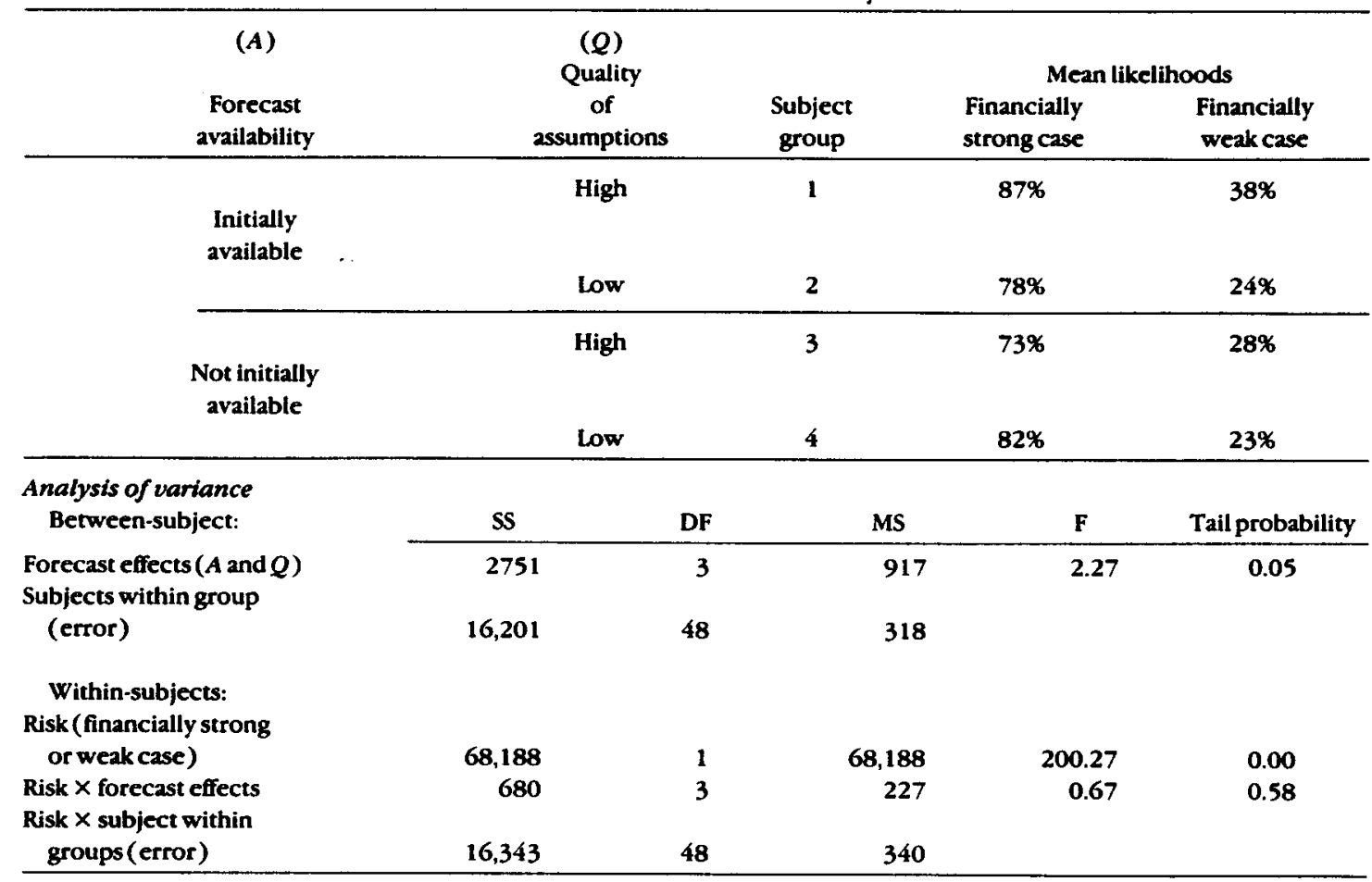

dence after seeing the initial (premeeting) data for both cases was quite high, and the data provided subsequently in phase 2 and phase 3 seemed to have an overall confirming effect on the lenders' confidence in their grant/not grant predictions. These results suggest that lenders reach a very high level of confidence early in the process based on highly summarized financial accounting information and other general background data. Further, while lenders continue to register significant increases in confidence as additional data are received, seldom does subsequent information cause them to alter their initial grant/not grant judgment. Still, they react significantly in the expected way to incremental data which confirm or disconfirm their prior be. liefs, as evidenced by the impact of the manipu. lated accounting variables.

Several conclusions can be drawn from this study. First, it confirms the overall importance of historical and forward-looking accounting information in the lending decision process. These accounting data are typically obtained at two points for new clients: first from independent credit-rating services in a summarized yet informative financial profile; and second, from the clients themselves. Both sources of historical data appear to be important. Since the historical accounting data independently processed by credit-rating services appears to have a significant early impact on the credit-granting decision process, and because the use of these services is pervasive among lending institutions, a great deal of insight might be gained by further investigations of precisely how these services use GAAP financial statements, and how they differentiate between GAAP and non GAAP accounting procedures in performing their credit evaluation service.

This evidence is consistent with the contention that prospective accounting data are used as signals of management planning competence. Providing well-grounded, forward-looking data for lender examination seems to signal credit 
worthiness. The results also tell us something about how lenders make decisions. Experienced lenders do modify their confidence as new infor- mation is processed, even where the signals disconfirm their prior positions.

\section{BIBLIOGRAPHY}

Brown, P., Foster, G. \& Noreen, E., Security Analysts Multi-Year Earnings Forecasts and the Capital Market (Sarasota, FL: American Accounting Association, 1985).

Danos, P., Holt, D. \& Imhoff, E., Bondraters' Use of Management Financial Forecasts: An Experiment in Expert Judgment, The Accounting Review (October 1984) pp. 547-573.

Einhorn, H. \& Hogarth, R., A Theory of Diagnostic Inference: Imagination and the Psychophysics of Evidence, working paper (June 1982).

Einhorn, H. \& Hogarth, R., Confidence in Judgment: Persistence of the Illusion of Validity, Psycbological Review (September 1978) pp. 395-416.

Ebbesen, E. \& Konecni, V., Decision Making and Information Integration in the Courts: The Setting of Bail, Journal of Personality and Social Psychology (1975) pp. 805-821.

Elstein, A., Shulman, L \& Sprafka, S., Medical Problem Solving: an Analysis of Clinical Reasoning (Cambridge, MA: Harvard University Press, 1978).

Financial Accounting Standards Board, Statement of Financial Accounting Concepts No. 1: Objectives of Financial Reporting by Business Enterprises (Stamford, CT: FASB, 1978).

Holt, D., Evidence Integration in the Formation of Risk Assessments by Auditors and Bank-lending Officers, dissertation, The University of Michigan (1984).

Koriat, A., Lichtenstein, S. \& Fischhof, B., Reasons for Confidence, Journal of Experimental Psychology: Human Learning and Memory (March 1980) pp. 107-1 18.

Libby, R., The Impact of Uncertainty Reporting on the Loan Decision, Supplement toJoumal of Accounting Researcb (Spring 1979) pp. 35-57.

Lord, C. G., Ross, L \& Lepper, M. R., Biased Assimilation and Attitude Polarization: The Effect of Prior Theories of Subsequently Considered Evidence, Journal of Personality and Social Psychology (November 1979) pp. $2098-2109$.

Oskamp, S., Overconfidence in Case Study Judgments, The Joumal of Consulting Psychology (1965) pp. 261-265. 